\title{
USO E OCUPAÇÃO DA TERRA NA BACIA HIDROGRÁFICA DO RIO BRANCO, AFLUENTE DA MARGEM ESQUERDA DO RIO CABAÇAL, MATO GROSSO
}

\author{
Josiel Dorriguette de Oliveira ${ }^{(1)}$, Célia Alves de Souza ${ }^{(2)}$, Juberto Babilônia de Sousa ${ }^{(3)}$, Vinicius \\ Neves da Silva ${ }^{(4)}$ \\ (1) Pós-graduação em Ciências Ambientais/ Universidade do Estado de Mato Grosso, dorriguette@ gmail.com \\ (2) Departamento de Geografia/ Universidade do Estado de Mato Grosso, celiaalvesgeo@ globo.com \\ (3) Instituto Federal de Mato Grosso/Cáceres, jubertobabilonia@yahoo.com.br \\ (4) Departamento de Geografia/ Universidade do Estado de Mato Grosso, vinicius.k99@ gmail.com
}

Eixo: Uso e ocupação das terras e legislação ambiental

\begin{abstract}
Resumo
O estudo do uso e ocupação da terra possibilita compreender como a dinâmica social na bacia contribuiu para as alterações no meio. O objetivo foi identificar diferentes tipos de ocupação e usos da terra. A metodologia consistiu em: análise bibliográfica; interpretação de mapas temáticos; e visitas in loco. Os dados sobre a ocupação e o uso da bacia foram disponibilizados através do Anuário Estatístico de Mato Grosso e IBGE. Realizou-se uma revisão bibliográfica sobre a ocupação da área. Para a análise do uso da terra, foi feita interpretação de mapas temáticos. Foram realizadas visitas in loco com observação direta da área de estudo. Com esse estudo foi possível identificar as relações humanas com as características ambientais, por meio da análise das formas de uso, ocupação e manejo desempenhados pelos produtores rurais mostrando a necessidade do envolvimento desses, com práticas agrícolas sustentáveis a fim de atender as necessidades sociais e ambientais.
\end{abstract}

Palavras chave: Colonização; Impactos ambientais; produção.

\section{Introdução}

Segundo Araujo, Almeida e Guerra (2005), a terra é definida como uma área delineável da superfície sólida de nosso planeta onde se inclui todos os atributos da biosfera. Essa classificação inclui o modelo de assentamento, as atividades e os resultados produzidos pelos seres humanos no passado e no presente.

Para Santos (2007), o território não deve ser entendido apenas como um conjunto de sistemas naturais com coisas superpostas, mas sim analisado levando em consideração o seu uso. O autor acrescenta ainda que o território usado precisa ser compreendido como o "chão mais a identidade". Assim, ao analisar uma determinada porção do território, torna-se necessário perceber as diversas dinâmicas que ali interagem, nunca desconectando a identidade daqueles que ocupam o espaço determinado.

Conforme apontado por Barros (2000), o governo militar usou de discursos nacionalistas, tais como "Integrar para não entregar" e "Terras sem homens para homens sem terras", para realizar a colonização 
do Oeste brasileiro a partir da segunda metade do século XX. Essa colonização a qualquer custo atraía colonos oriundos dos diversos rincões do Brasil, que almejavam ocupar o "vazio" existente principalmente na Amazônia brasileira.

Diante da importância dos estudos sobre o uso e ocupação da terra nas bacias hidrográficas, alguns trabalhos podem ser destacados, tais como: Santos (2014), na bacia hidrográfica do córrego Cachoeirinha; Silva (2009), trabalhando a dinâmica fluvial e o processo de ocupação, como proposta de gestão dos recursos hídricos na bacia hidrográfica do córrego das Pitas, MT; Souza e Cunha (2012), analisando a evolução das margens do rio Paraguai entre a cidade de Cáceres e a estação ecológica da Ilha de Taiamã, MT.

O objetivo deste estudo foi verificar o processo do uso e ocupação da terra e a transformação socioambiental ocorrida na bacia hidrográfica do rio Branco, afluente da margem esquerda do rio Cabaçal, localizada no sudoeste do Estado de Mato Grosso, nos municípios de Reserva do Cabaçal, Salto do Céu, Rio Branco e Lambari D’Oeste.

\section{Materiais e métodos}

\section{1. Área de estudo}

A bacia do rio Branco localiza-se entre as coordenadas geográficas de $14^{\circ} 59^{\prime}$ '00" a $15^{\circ} 20^{\prime} 00^{\prime \prime}$ de latitude

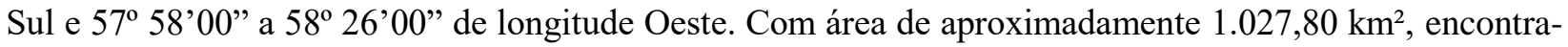
se entre os municípios de Reserva do Cabaçal, Salto do Céu, Rio Branco e Lambari D’Oeste no sudoeste do estado de Mato Grosso. A bacia possui cerca de 100 afluentes, tendo como principal afluente o córrego Bracinho.

\subsection{Procedimentos metodológicos}

O levantamento do tipo de uso e ocupação da bacia hidrográfica do rio Branco foi realizado em três etapas: análise documental, interpretação de mapas temáticos e pesquisa de campo.

\subsubsection{Análise documental e bibliográfica}

Segundo Lakatos e Marconi (2003) as pesquisas documentais são baseadas restritamente a documentos, escritos ou não, que são entendidos como fontes primárias. Assim, as pesquisas documentais consistiram em consultas às bibliografias acerca da bacia hidrográfica do rio Branco. 
Foram analisados artigos científicos, livros e dados estatísticos do IBGE e da Secretaria de Planejamento do Estado de Mato Grosso (SEPLAN), no sentido de identificar os diferentes tipos de uso da terra.

\subsubsection{Interpretação dos mapas temáticos}

Os mapas de localização foram realizados a partir das folhas topográficas do IBGE, em escala de 1:100.000. O mapa de uso da terra foi realizado a partir da extração dos dados do Projeto Terra Class 2010 (PRODES/IMPE) que tem como objetivo qualificar o desflorestamento da Amazônia Legal. Os dados digitais resultantes do mapeamento encontram-se disponíveis para download, divididos em suas respectivas órbitas-ponto do satélite Landsat5 (sensor TM), no Sistema de Projeção Lat/Long e Sistema Geodésico de Referência SAD 69.

As atualizações para a situação do uso da terra no ano de 2015 foram realizadas a partir do software ArcGis, versão 10.1, com imagens de satélite LANDSAT TM5 e TM8, em escala 1: 250.000 com confirmação e adequação dos resultados a partir das atividades de campo. Essas imagens subsidiaram análise e interpretação dos dados obtidos nas pesquisas bibliográficas.

\subsubsection{Pesquisa de campo}

A pesquisa de campo tem como objetivo buscar informações e/ou conhecimentos acerca da problemática estudada. Nessa fase, o pesquisador pode observar como os fenômenos ocorrem espontaneamente, realizar coleta de dados e fazer o registro de variáveis que julgue relevante à pesquisa. Essa fase ocorre após a realização do estudo bibliográfico, para que se tenha um bom conhecimento sobre o tema, pois é nessa etapa que são definidos os objetivos da pesquisa, as hipóteses, o procedimento de coleta de dados, o tamanho da amostra e o modo como os dados serão tabulados e analisados (MARCONI; LAKATOS, 2003).

Foram realizadas visitas a campo para observação direta da área de estudo, com o objetivo de confirmar os dados obtidos tanto pelas pesquisas documentais, quanto pelo mapa de uso e ocupação.

\section{Resultados e discussões}

\subsection{O processo de uso e ocupação da terra na bacia hidrográfica do rio Branco}

$\mathrm{Na}$ bacia foram encontrados restos de objetos de cerâmica em localidades como Baixo Pito, Corgão e Canaã pelos colonos; porém, a falta de estudos antropológicos impossibilita a datação e a determinação da 
procedência de tais objetos. Acredita-se que esses itens cerâmicos pertenceram aos índios Cabaçais que habitavam a região, subindo os rios Cabaçal, Branco e Vermelho. Esses índios foram "pacificados" e aldeados na região do rio Jauru em 1942, deslocando-se da região de Rio Branco (MOURA, 1994).

Com a abertura do porto de Corumbá, em 1870, a região de Cáceres passou a ter acesso ao comércio exterior via rio Paraguai. Assim, a região de Rio Branco passou a ser explorada por poaieiros, caçadores de animais e madeireiros. A produção extrativista era escoada pelos rios Sepotuba e Cabaçal até Cáceres, de onde seguia até Corumbá para ser encaminhada aos mercados nacionais e internacionais (MOURA, 1994).

Na margem esquerda do rio Branco em 1947, o governo do Estado de Mato Grosso iniciou a venda de áreas em torno de 10.000 ha a preços reduzidos para particulares, com o objetivo de povoar a área. Assim, extensas áreas de terras foram vendidas (MOURA, 1994).

Na margem direita do Rio Branco, com o intuito de incentivar o povoamento da região, o governo do Estado, a partir do Decreto $\mathrm{n}^{\circ} 1598$, de 22/05/1953, reservou para colonização as terras devolutas de domínio do Estado situadas entre os rios: Branco (ao leste), Bugre (ao oeste), a Serra dos Parecis (ao norte) e da barra do rio Branco até a foz do rio Bugre (ao sul). Para que fosse realizada a colonização, o governo do Estado celebrou um contrato de seis anos com a Colonizadora MADI S/A - C.A.E.C, para que promovesse o povoamento da área e a venda dos lotes aos colonos (MOURA, 1994).

Como a colonizadora MADI não cumpriu o contrato firmado com o governo do Estado, a região acabou não sendo colonizada. Fato confirmado pelo então presidente da Comissão de Planejamento da Produção (CPP), João Augusto Capilé Junior, que visitou a região, passando pelas terras de Airton Montechi e atravessou o rio Branco, onde encontrou terras férteis e vazias, com nenhum sinal de ocupação (FERREIRA, 2001).

A partir do ano de 1962, começaram a chegar as primeiras famílias vindas da Fazenda Tavares de Porto Vilma (MS). Doravante, o governo do Estado designou o Eng. Mauricio Madureira para fazer o loteamento do restante dos lotes, divididos entre 15 e 120 ha, conforme fertilidade e textura do solo, que passou a ser denominado Colônia Rio Branco (MOURA, 1994).

Em 1963, iniciou-se a distribuição dos lotes aos colonos que estavam à espera de terras nos povoados de Panorama e Lambari. Os títulos definitivos não negociáveis passaram a ser emitidos em 1965, através do Departamento de Terras e Colonização (DTC) e CPP, com áreas de 15 a 25 ha para cada assentado da Colônia Rio Branco. Esse trabalho passou posteriormente para a competência da Companhia de Desenvolvimento de Mato Grosso (CODEMAT). 
Segundo Moura (1994), dos 200.000 ha reservados pelo Decreto $n^{\circ} 1.598$ foram usados efetivamente para a Colônia Rio Branco, 113.488 hectares, nos quais são encontrados hoje os municípios de Rio Branco, Reserva do Cabaçal, Salto do Céu e parte de Barra dos Bugres.

A Colonizadora Rio Branco não cumpriu com planejamentos de assistência aos colonos, como saúde, educação e transporte. Dezenas de famílias começaram a vender seus lotes, objetivando adquirir terras mais baratas e gratuitas em outras áreas e Estados (FERREIRA, 2001).

As populações dos municípios que formam a bacia hidrográfica do rio Branco passaram por uma redução, observada a partir do ano de 1991. Esse decréscimo é resultado das dificuldades encontradas pelos colonos durante o processo de colonização. Os principais problemas são ocasionados pela falta de assistência técnica e financeira por parte do Estado. A abertura de novos assentamentos no norte de Mato Grosso e Rondônia foi outro grande incentivo para que os colonos vendessem suas terras e migrassem para essas regiões.

Analisando os resultados da contagem populacional, é possível observar a decadência populacional ocorrida na área da bacia (Tabela I).

Tabela I - População dos municípios de Lambari D’Oeste, Reserva do Cabaçal, Rio Branco e Salto do Céu no período de 1980 a 2016.

\begin{tabular}{ccccccccc}
\hline Município & $\mathbf{1 9 8 0}$ & $\mathbf{1 9 8 5}$ & $\mathbf{1 9 9 1}$ & $\mathbf{1 9 9 6}$ & $\mathbf{2 0 0 0}$ & $\mathbf{2 0 1 0}$ & $\mathbf{2 0 1 6}$ & $\begin{array}{c}\text { Dens. hab/km } \\
\mathbf{2 0 1 0}\end{array}$ \\
\hline Lambari D'Oeste & - & & - & 5.784 & 4.683 & 5.431 & 5.831 & 3,08 \\
Reserva do Cabaçal & - & & 3.186 & 2.789 & 2.421 & 2.572 & 2.638 & 1,92 \\
Rio Branco & 17.583 & 24.517 & 11.845 & 5.730 & 5.072 & 5.070 & 5.028 & 9,01 \\
Salto do Céu & 11.249 & 15.503 & 7.410 & 5.669 & 5.513 & 3.908 & 3.423 & 2,23 \\
\hline
\end{tabular}

No Censo de 1980, o município de Rio Branco, que na época integrava também os territórios onde hoje estão os municípios de Reserva do Cabaçal e Lambari D' Oeste, possuía uma população de 17.583 habitantes. De acordo com a estimativa do Anuário Estatístico de Mato Grosso, sua população em 1985 era de 24.517. No Censo de 1991, foram contabilizados 15.031 habitantes (Rio Branco e Reserva do Cabaçal) e no de 2010 essa população foi reduzida para 13.073 habitantes (Rio Branco, Reserva do Cabaçal e Lambari D’ Oeste).

O município de Salto do Céu, no Censo de 1980, tinha 11.249 habitantes. Pela estimativa do Anuário Estatístico de Mato Grosso, o distrito possuía, em 1985, uma população de 15.503 habitantes. Esse número-foi reduzindo e, para o ano de 2016, o IBGE estima uma população de 3.423 habitantes.

O primeiro Censo efetuado em Reserva do Cabaçal, como município emancipado, ocorreu em 1991, quando sua população era de 3.186 habitantes. De acordo com a estimativa para o ano de 2016, sua população é de 2.638 habitantes. 
O município de Lambari D’Oeste, em 1996, possuía uma população de 5.784 habitantes. No Censo de 2000, sua população havia sido reduzida para 4.683 habitantes. De acordo com a estimativa de 2016, sua população atual é de 5.831 habitantes. Dos quatro municípios da bacia hidrográfica do rio Branco, o município de Lambari D' Oeste é o único que está passando por um processo de aumento da população e esse crescimento populacional pode ser creditado à Destilaria de Álcool COPERB que necessita da mão de obra local para sua operação.

O ápice de ocupação nos anos amostrados ocorreu em 1985. Nessa época, nos municípios que integram a bacia, viviam 40.020 pessoas. Em 1991, essa população passou a ser de 22.441. Ocorreu, portanto, uma redução de 43,92\% em seis anos. A redução populacional na bacia, embora menos intensa, continuou nos anos seguintes, chegando a 16.920 pessoas em 2016. Sendo assim, até 2016 houve uma redução de $57,72 \%$ na população, se comparado a 1985.

\subsubsection{Processo de ocupação dos municípios da bacia hidrográfica do rio Branco}

O município de Rio Branco situa-se em parte da área formada pela então Colônia Rio Branco. O nome Rio Branco deu-se em decorrência ao rio de mesmo nome que corta o município e o centro urbano. $\mathrm{O}$ nome do rio foi escolhido pelos primeiros exploradores, em virtude de suas águas límpidas.

Segundo Ferreira (2001), João Augusto Capilé Filho, o presidente da Comissão de Planejamento e Produção, que tinha como função o assentamento de colonos no Estado de Mato Grosso, subiu às margens do rio Branco em busca de terras de boa qualidade, que, naquela época, era identificada pelos tipos de árvores presentes. Deparando-se com uma grande queda d'água no rio Branco, denominou-a de Salto do Céu, nome esse posteriormente dado ao município.

Segundo Ferreira (2001), na Fazenda Itaguay, distante dez quilômetros de Reserva do Cabaçal, em 1967, cerca cento e cinquenta homens que trabalhavam como diaristas no cultivo da terra perceberam que, do outro lado do rio, na margem esquerda, existiam terras devolutas. Ao final de seus contratos com a fazenda, deslocaram-se para essas terras, tomando a posse de alguns lotes à espera da CODEMAT, que foi posteriormente fazer as demarcações definitivas em lotes de 15 a 25 hectares. O nome do município foi dado pela Companhia de Desenvolvimento do Estado de Mato Grosso - CODEMAT, juntamente com os fundadores (pioneiros), que deram início à colonização da então "Colônia Rio Branco", em 1967. Havia ficado definido que essa área seria uma "reserva" e, pelo fato de estar à margem esquerda do rio Cabaçal, convencionou-se chamá-la de Reserva do Cabaçal. 


\section{OS DESAFIOS DA GEOGRAFIA FÍSICA NA FRONTEIRA DO CONHECIMENTO \\ Instituto de Geociências - Unicamp \\ Campinas - SP \\ 28 de Junho à 02 de Julho de 2017}

Segundo Ferreira (2001), o nome escolhido para o povoado foi dado em razão do córrego chamado de Lambari, que cortava o povoado onde atualmente se encontra a sede do município. O córrego recebeu esse nome devido à grande quantidade de peixes nele encontrada, sendo mais abundante os do tipo "Lambari".

A primeira atividade econômica desenvolvida na bacia foi a retirada da poaia, planta utilizada para fins farmacêuticos. A agricultura teve início com o cultivo do arroz e do feijão, que impulsionou o desenvolvimento da população, a qual era formada principalmente por mineiros e capixabas que habitaram a região (FERREIRA, 2001).

O que se pode observar, seguindo uma tendência mundial e principalmente brasileira, é que o pequeno proprietário não consegue manter-se no campo no instante em que se vê incapaz de concorrer com a produção mecanizada. A partir desse momento, os pequenos proprietários passaram a vender suas propriedades e tornarem-se parte de uma população urbana; as propriedades rurais na maior parte da bacia passam a ser utilizadas para a bovinocultura e as produções agrícolas foram reduzidas (Tabela II).

No município de Lambari D’Oeste as migrações populacionais para outras regiões e o crescimento das áreas plantadas com cana-de-açúcar, fez com que muitos produtores vendessem suas propriedades e as lavouras passaram a ocupar boa parte do território. Assim, as produções das outras culturas agrícolas praticamente desapareceram. A produção local de cana-de-açúcar é beneficiada na Cooperativa Agrícola dos Produtores de Cana de Rio - COOPERB, situada no município.

Tabela II - Principais culturas anuais e pecuária no município de Rio Branco entre os anos de 1981 e 2014.

\begin{tabular}{ccccccc}
\hline \multicolumn{7}{c}{ PRINCIPAIS CULTURAS ANUAIS (MUNICÍPIOS QUE COMPÔEM A BHRB). } \\
\hline & $\mathbf{1 9 8 1}$ & $\mathbf{1 9 8 5}$ & $\mathbf{1 9 8 9}$ & $\mathbf{1 9 9 9}$ & $\mathbf{2 0 0 9}$ & $\mathbf{2 0 1 4}$ \\
Arroz (t) & 32.363 & 15.398 & 11.508 & 2071 & 391 & - \\
Feijão (t) & 2.166 & 4.096 & 2.378 & 506 & 113 & 88 \\
Milho (t) & 14.690 & 16.455 & 11.554 & 8785 & 1814 & 1345 \\
Mandioca (t) & 1.500 & 3.000 & 3.900 & 1530 & 2164 & 6630 \\
Café (t) & 2.040 & 1.899 & 1.277 & 74 & - & - \\
Banana $^{1}$ & 16 & 136 & 547 & 128 & 112 & 210 \\
Algodão (t) & 200 & 45 & 875 & 225 & - & - \\
Cana de açúcar (t) & 1.600 & 3.480 & 184.970 & 337.548 & 945.776 & 952.154 \\
Látex (t) & \multicolumn{7}{c}{ PECUÁRIA } & 137 & 104 & 101 \\
\hline & 112.652 & 111.932 & 154.141 & 264.843 & 331.926 & 394.561 \\
\hline Bovino & 30.095 & 20.714 & 29.536 & 7.621 & 7.212 & 4.600 \\
Suínos & 154.672 & 142.604 & 196.266 & 84.491 & 316.626 & 411.310 \\
Aves & \multicolumn{7}{c}{}
\end{tabular}

A produção de cereais nos municípios que compõem a bacia, que no ano de 1981 era de 49.219 toneladas, foi reduzida para 1433 toneladas em 2014. O arroz, que era o principal produto agrícola em 1981, em 2014 não registrou produção. Na cidade de Rio Branco havia três beneficiadoras de arroz e uma em Salto 


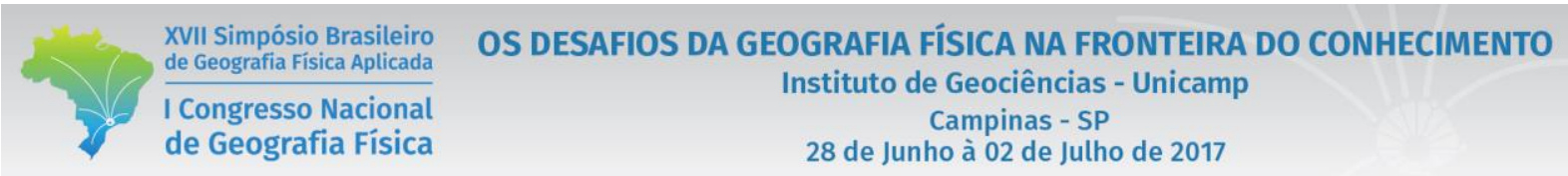

do Céu, hoje todas encerraram suas atividades. A mandioca, em 2014, era o principal produto agrícola produzido na bacia.

Na pecuária, houve redução na criação de suínos; diminuição explicada pelo fato de que esses animais eram criados pelos pequenos produtores que migraram para outras regiões. A criação de aves que estava em processo de redução até o ano de 1.999 e teve sua produção aumentada devido a um projeto desenvolvido em Reserva do Cabaçal chamado de Casulo que estimulou a produção de frangos pelos produtores para serem abatidos em frigorífico. A criação de bovinos firmou-se como a principal atividade agropecuária nos municípios de Rio Branco, Salto do Céu e Lambari D’Oeste. Em 1981, o rebanho era de 112.652 cabeças e em 2014 o rebanho passou para 394.561 cabeças. A escolha pela criação de bovinos nesses municípios deveu-se à concentração de terras e ao relevo acidentado da maior parte do território, fato que limitou a mecanização da produção. Como resultado dessa opção, a oferta de emprego foi reduzida, o que favoreceu o esvaziamento populacional do município.

\subsection{Ocupação atual da bacia hidrográfica do rio Branco}

Segundo as informações do mapa temático de unidades de uso e ocupação, no ano de 2015, o pasto limpo ocupava a maior área da bacia, com 69,48\%; a vegetação secundária 10,59\%; a floresta 6,35\%; o cerrado 4,93\%; o pasto sujo 4,64\%; a agricultura anual 1,95\%; o pasto em regeneração $0,93 \%$; a silvicultura 0,53\%; a área urbana 0,33\%; e a área ocupada pelo espelho d'água correspondia a 0,27\% (Figura 1).

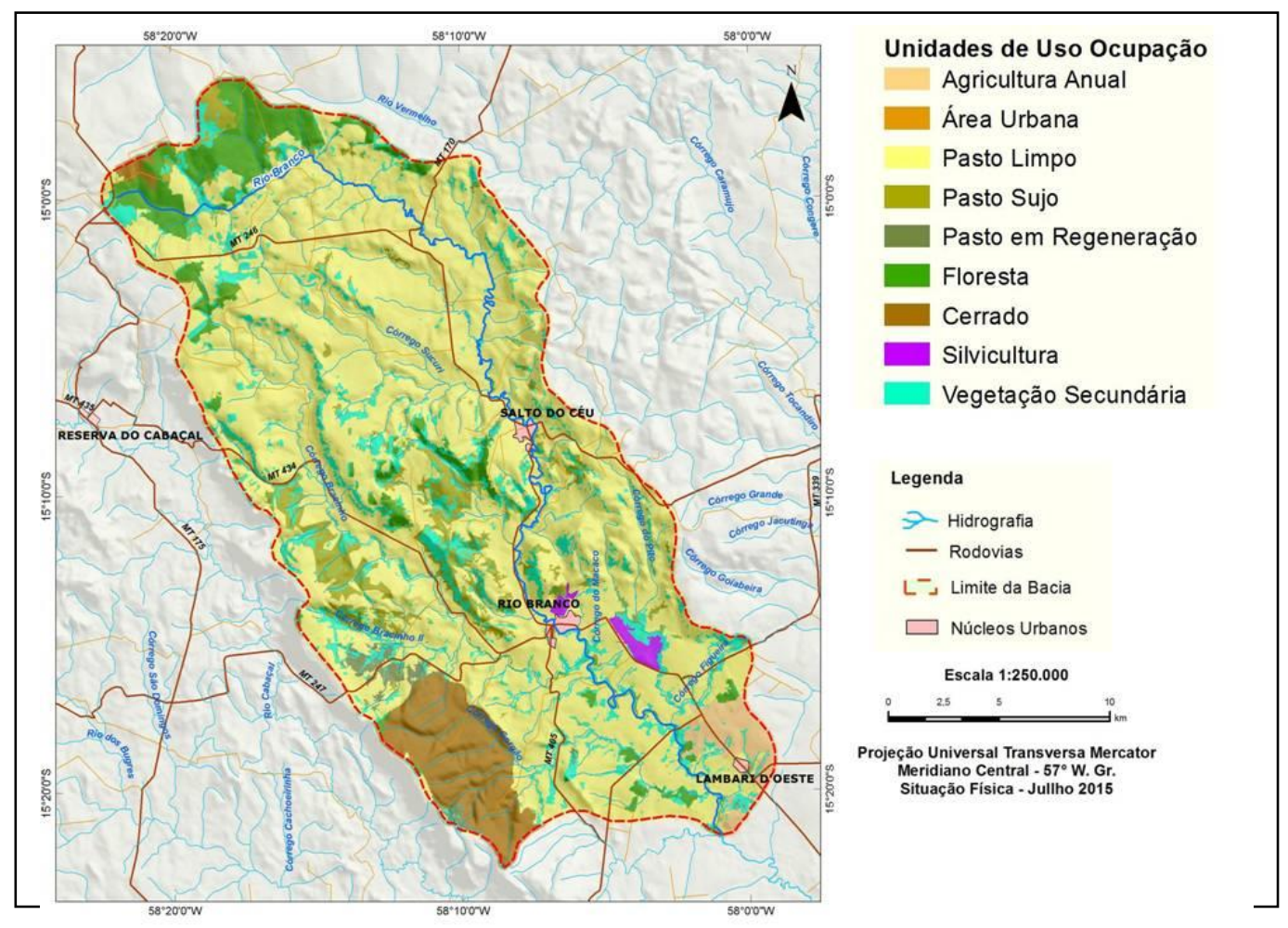




\section{OS DESAFIOS DA GEOGRAFIA FÍSICA NA FRONTEIRA DO CONHECIMENTO \\ Instituto de Geociências - Unicamp \\ Campinas - SP \\ 28 de Junho à 02 de Julho de 2017}

Figura 1: Unidades de uso e ocupação da bacia hidrográfica do rio Branco.

O relevo acidentado que se apresenta por quase toda a bacia inibe a produção mecanizada na maior parte das áreas. Assim, a bovinocultura foi a atividade econômica encontrada pelos produtores para ser desempenhada em suas propriedades. Há algumas pequenas áreas destinadas à silvicultura e à agricultura.

\subsubsection{Pastagens}

As pastagens ocupam cerca de $75 \%$ da área da bacia hidrográfica do rio Branco. Nelas, a principal atividade econômica é a bovinocultura destinada à produção de leite, cria, recria, engorda e abate.

A produção de leite é realizada principalmente nas pequenas e médias propriedades, locais em que geralmente predominam áreas com solos menos férteis e com relevos mais movimentados.

Os solos encontrados nos relevos mais suaves são ocupados geralmente por grandes propriedades rurais. Nessas áreas, a mecanização facilita o manejo do solo e dos animais; nelas, predominam a criação de gado bovino destinado ao abate. Os principais frigoríficos que atendem à demanda da bacia são o MARFRIG, de Tangará da Serra, o NATURAFRIG de Barra dos Bugres, o JBS, de Araputanga, e o MINERVA, de Cuiabá.

\subsubsection{Agricultura anual}

As áreas destinadas à agricultura ocupam apenas 1,95\% da área da bacia hidrográfica do rio Branco, as quais são usadas basicamente para a produção de cana-de-açúcar.

Algumas propriedades rurais possuem pequenas lavouras onde é encontrada a produção de alimentos destinados geralmente ao consumo local e regional. As principais lavouras observadas são de verduras, legumes, mandioca, banana, milho e cana-de-açúcar.

No baixo curso do rio Branco, é encontrada a produção de cana-de- açúcar, sendo essa atividade a

principal produção agrícola da bacia. A cana-de-açúcar é beneficiada na Cooperativa Agrícola dos Produtores de Cana de Rio Branco (COOPERB), situada no município de Lambari D’ Oeste.

\subsubsection{Silvicultura}


A silvicultura ocupa $0,53 \%$ da área da bacia hidrográfica do rio Branco e sua produção destina-se à produção de látex e de madeira.

Das seringueiras (Hevea brasiliensis) plantadas às margens da Rodovia MT-170, no município de Rio Branco, é extraído o látex. Como a produção é pequena, não existe indústria de processamento do produto no local; assim, o item é exportado in natura.

A produção de madeira é destinada principalmente à indústria moveleira. A principal espécie encontrada é a Teca (Tectona grandis), porém também há outras madeiras de lei em menor escala. A produção é praticamente toda beneficiada na indústria Rossima Madeiras, situada na cidade de Rio Branco, que vende a madeira beneficiada e também produz painéis, portas, portais, entre outros.

\subsubsection{Florestas}

As florestas ocupam 6,35\% da bacia hidrográfica do rio Branco. A maior porção de floresta é encontrada na área de nascente do rio Branco no extremo norte da bacia. Outros ambientes de floresta compreendem apenas algumas pequenas áreas de preservação permanente, distribuídas ao longo da bacia.

\subsubsection{Cerrado}

O remanescente de Cerrado corresponde a 4,93\% da área da bacia hidrográfica do rio Branco. Essa área possui limitação ao uso, devido às características físicas do relevo e do solo que desfavorecem o seu uso, aliado ao relevo movimentado, dificulta o manejo, tornando-se impróprio para as atividades econômicas.

\subsubsection{Vegetação secundária}

A vegetação secundária é encontrada geralmente nos topos de morros, nas escarpas e nas margens dos canais de drenagem, ocupando 10,59\% da área da bacia hidrográfica do rio Branco.

\subsection{Consequências da ocupação atual}

O impacto mais evidente e que traz muita preocupação na área da bacia do rio Branco é o desmatamento ocorrido com a ocupação, que não levou em consideração as legislações ambientais; assim, houve o desmatamento intensivo das matas, inclusive da mata ciliar. $\mathrm{O}$ desmatamento intensivo, aliado à falta de 
manejo, trouxe diversos impactos ambientais, tais como a degradação do solo, assoreamento dos córregos e alteração no padrão de drenagem.

Outro grave problema na bacia encontra-sena área de cabeceira de drenagem e está associado à presença de processos erosivos. As políticas de ocupação, sem levar em consideração as características ambientais, ocasionaram o uso incoerente diante das características físicas e químicas do solo. Nessa área, predomina o Neossolo Quartzarênico, sendo esse solo muito suscetível a processos erosivos, devido à fragilidade natural.

A bacia foi intensamente desmatada a partir da década de 1960, quando se iniciou o processo de ocupação da área. Desde então, observa-se um ataque devastador às florestas para retirada de madeira, bem como para ocupar a área para a produção agropecuária. Nesse processo, não se teve o cuidado em respeitar às leis ambientais, ocorreu também uma omissão do Estado, resultando em uma bacia totalmente vulnerável.

O intenso desmatamento causa uma diminuição da infiltração da água das chuvas associadas a um aumento do escoamento superficial. Como consequência, ocorre uma redução das reservas hídricas nos lençóis subterrâneos. Assim, com a redução das reservas de recargas dos córregos e a intensa sedimentação potencializada pela falta de vegetação nas margens dos córregos, é observada uma intensa degradação nos canais que compõem a bacia.

\section{Considerações finais}

A região que abrange a bacia do rio Branco era habitada por indígenas. A colonização iniciou-se com a criação, em 22 de maio de 1953, da Colônia Rio Branco; todavia, a ocupação efetivou-se na década de 1960. As terras da margem direita do rio Branco foram doadas pelo do governo do Estado e as terras da margem esquerda foram loteadas e disponibilizadas para a venda através de projetos de colonização.

Os dados estáticos demonstram que a produção de cereais era a principal atividade desempenhada na bacia na década de 1980, porém essa vocação agrícola foi perdendo-se na bacia e, hodiernamente, a bacia é ocupada principalmente para o desempenho da bovinocultura. Em menor escala, são observadas outras atividades econômicas de ocupação da terra, tais como a agricultura anual e a silvicultura.

A população residente nos municípios que compreendem a bacia reduziu de 40.020 pessoas, em 1985 , para 16.920 pessoas, em 2016. Essa diminuição ocorreu devido à concentração de terras na bacia, que levaram a população a se direcionar para outras regiões mais dinâmicas do país. Dos municípios que compreendem a bacia, Lambari D’Oeste é o único que representa aumento populacional na década de 
2010, o que pode ser explicado pela presença de uma usina de álcool que garante emprego à população local.

Os municípios de Salto do Céu e Rio Branco são os que ocupam a maior parte da bacia; e os municípios de Reserva do Cabaçal e Lambari D’Oeste ocupam áreas menores. O município de Rio Branco possui $71,70 \%$ do seu território ocupado pela bacia hidrográfica do rio Branco, sendo o mais dependente dela.

A falta de manejo adequado do solo e de práticas conservacionistas estão causando diversos impactos na bacia, sendo que os mais evidentes são: a degradação do solo, o assoreamento dos córregos e as alterações no padrão de drenagem. As áreas de preservação permanente geralmente são inexistentes, sendo constatada a falta de mata ciliar em praticamente toda a bacia. Nas áreas de cabeceira de drenagem, os processos erosivos causam assoreamento dos canais, a falta de barreira natural para as águas pluviais reduz a recarga do lençol freático e acelera o escoamento superficial, causando enchentes.

Desse modo, evidencia-se a necessidade de ações objetivas e conjuntas, envolvendo a comunidade (pequenos, médios e grandes proprietários de terra) e os órgãos públicos gestores, para que esses agentes possam conhecer as ações de degradação dos recursos naturais da bacia do rio Branco e as respectivas consequências. O gerenciamento ambiental é de suma importância; mas, se não envolver os ocupantes e as suas formas de uso, torna-se uma ação ineficaz.

\section{Bibliografia}

ARAUJO, G. H. de S; ALMEIDA, J. R; GUERRA, A. J. T. Gestão ambiental de áreas degradadas. Rio de Janeiro/RJ: Ed. Bertrand Brasil, 2005.

BARROS, A. (Coord.). Sustentabilidade e democracia para as políticas públicas da Amazônia. Rio de Janeiro: FASE, 2000. (Cadernos de Debate Brasil Sustentável e Democrático, 8).

BARROZO, J. C. Os assentados e os assentamentos rurais do Araguaia. In: MARLUZA, M. H; VITALE, J. (Org.). História, terra e trabalho em Mato Grosso. São Leopoldo, UNISINOS. UDEFMT, Cuiabá. 2008.

DEFACIO, M. A. R.A complexidade do processo de regularização da Gleba Boa Vontade - Rio Branco e Salto do Céu - Mato Grosso e as políticas estaduais de alienação de terras públicas - 1973-2000. TCC. Dep. de História, Universidade do Estado de Mato Grosso, Cáceres: 2002.

FEARNSIDE, Philip M. Desmatamento na Amazônia Legal brasileira: história, índices e consequências. Megadiversidade, v. 1, n. 1, p. 113-123, 2005.

FERREIRA, J. C. V. Mato Grosso e seus municípios. Secretaria de Estado de Educação, Cuiabá. 2001.

IBGE - Instituto Brasileiro de Geografia e Estatística. Disponível em:

<http://www.cidades.ibge.gov.br/xtras/uf.php?lang=\&coduf=51\&search=mato-grosso >. Acesso em: 04 mar.2016.

INPE - INSTITUTO NACIONAL DE PESQUISAS ESPACIAIS; EMBRAPA -EMPRESA BRASILEIRA DE PESQUISA AGROPECUÁRIA. TerraClass:Levantamento de Informações de uso e cobertura da terra na Amazônia,setembro de 2011.

LAKATOS, E. M.; MARCONI, M. A. Metodologia do trabalho científico. São Paulo: Editora Atlas, 2003. 


$\begin{aligned} & \text { XVII Simpósio Brasileiro } \\ & \text { de Geografia Fisica Aplicada }\end{aligned}$
$\begin{aligned} & \text { I Congresso Nacional } \\ & \text { de Geografia Física }\end{aligned}$

MATO GROSSO. Lein ${ }^{\circ} 8.090$ de 20 de janeiro de 2004. Dispõe sobre anexação de área ao Município de Reserva do Cabaçal e dá outras providências.PalácioPaiaguás, em Cuiabá, 20 de janeiro de 2004.Diário Oficial do Estado, Cuiabá, MT (20/04/2004).

MATO GROSSO. Secretaria de Planejamento e Coordenação Geral. Anuário Estatístico de Mato Grosso. Disponível em: <http://www.dados.mt.gov.br/ publicacoes/anuarios/>. Acesso em: 24 ago. 2016.

MOURA, A. E. Gleba Canaã - Estudo das Práticas Econômicas e Sociais de Camponeses Posseiros no Sudoeste Do Estado de Mato Grosso. Dissertação de Mestrado. UFRGS. Ano de Obtenção: 1994.

SANTOS, M. dos. Uso, ocupação da terra e dinâmica fluvial da bacia hidrográfica do córrego Cachoeirinha no município de Cáceres, Mato Grosso. 2013. 150f. Dissertação (Mestrado em Ciências Ambientais) - Programa de Pós-Graduação em Ciências Ambientais. Universidade do Estado de Mato Grosso, UNEMAT, Cáceres, MT, 2013.

SANTOS. O dinheiro e o território, In: SANTOS, M (Org.), Território, territórios: ensaios sobre o ordenamento territorial. Lamparina: Rio de Janeiro, 2007.

SILVA, C. A. F. Grupo André Maggi: corporação e rede em áreas de fronteira. Ed. Entrelinhas. Cuiabá, MT, 2003.

SILVA, L. N. P. Bacia hidrográfica do córrego das Pitas-MT: dinâmica fluvial e o processo de ocupação, como proposta de gestão dos recursos hídricos. 2009. 146 f. Dissertação (Mestrado em Ciências Ambientais) - Programa de Pós-Graduação em Ciências Ambientais. Universidade do Estado de Mato Grosso. Cáceres-MT, 2009.

SOUZA, C. A; CUNHA, S. B. Evolução das margens do rio Paraguai entre a cidade de Cáceres e a estação ecológica da Ilha de Taiamã, MT. In: SOUZA, C. A. (Org.) Bacia Hidrográfica do Rio Paraguai, MT: Dinâmica das águas, uso e ocupação e degradação ambiental. São Carlos: Editora Cubo, 2012. 